index •comunicación | no 12(1) 2022 | Páginas 77-98

E-ISSN: 2174-1859 | ISSN: 2444-3239 | Depósito Legal: M-19965-2015

Recibido el 15_09_2021 | Aceptado el 22_10_2021 | Publicado el 15_01_2022

\title{
NARRATIVA DE CAMPAÑA EN INSTAGRAM: ESPECTÁCULO Y AUTORREPRESENTACIÓN DE CANDIDATOS. EL CASO DE LAS ELECCIONES GENERALES 2019
}

CAMPAIGN NARRATIVE ON INSTAGRAM:

SPECTACLE AND CANDIDATE SELF-REPRESENTATION. THE CASE OF THE SPANISH 2019 GENERAL ELECTION

https://doi.org/10.33732/ixc/12/01Narrat

Carme Ferré-Pavia Universitat Autònoma de Barcelona

Carme.Ferre@uab.cat https://orcid.org/0000-0002-7258-6376

Mariona Codina

Universitat Autònoma de Barcelona

Mariona_11@hotmail.es https://orcid.org/0000-0002-1079-5922 
Resumen: Este artículo tiene como objetivo analizar las estrategias que usaron los partidos políticos en sus publicaciones en Instagram durante la campaña de las elecciones del 10 de noviembre de 2019, en términos de su contenido y recursos mediáticos, en un entorno de política-espectáculo. Se han analizado 655 publicaciones en total, procedentes de los partidos estatales y autonómicos catalanes, a través del análisis de contenido con mirada cuantitativa e interpretativa. Desde un punto de vista comparativo, se localiza una brecha entre los partidos de nueva y vieja política en el uso de Instagram y se evidencia que el recurso a la personalización varía entre formaciones. En el caso de los partidos catalanes, la campaña se mezcla con los efectos de la situación de sus exdirigentes. Con alguna excepción, las propuestas programáticas durante la campaña se difuminan en prácticamente todos los casos. Se concluye que, en Instagram, la narrativa electoral se construye como un relato de acciones autorreferenciales escenificadas, con el contexto de los sucesos políticos en el caso catalán.

Palabras clave: comunicación política; elecciones 2019; espectacularización; Instagram; campañas electorales, self-representation.

Abstract: This article aims to analyze the strategies used by political parties on Instagram posts during the election campaign of November 10, 2019, in terms of their content and media resources, in a politainment environment. A total of 655 publications were analyzed, coming from state and autonomous Catalan parties, through content analysis with quantitative and interpretative focus. From a comparative point of view, a gap is found between new and old political parties in the use of Instagram, and it is evident that the use of personalization varies between formations. In the case of Catalan parties, the campaign is mixed with the effects of the situation of their former leaders. With some exceptions, the programmatic proposals during the campaign are blurred in almost all cases. It is concluded that, on Instagram, the electoral narrative is constructed as a narrative of staged self-referential actions, with the context of the political events in the Catalan case.

Keywords: Political Communication; 2019 Elections; Spectacularization; Instagram; Electoral Campaigns; Self-representation. 


\section{Introducción}

Internet ha modificado radicalmente el estilo de vida cotidiano de prácticamente toda la población y ha supuesto un paso adelante en términos de progreso humano (Costa, Rodríguez y López, 2020). Las redes sociales han generado un nuevo ecosistema de comunicación y la política no ha sido ajena a ello (Ohme, 2019a, 2019b; Meilán, 2018). Esta investigación pretende acercarse a las estrategias digitales de los partidos y para ello se han analizado 655 publicaciones difundidas en Instagram de los partidos estatales y autonómicos catalanes: PSOE, PP, Vox, Unidas Podemos, ERC, Ciudadanos, Junts per Catalunya, Más País y la CUP. Escoger el caso catalán supone tener un arco de partidos más amplio y que difiere del eje izquierda-derecha o vieja-nueva política, incorporando otros posibles seguidores.

La revisión de la red escogida, Instagram, completa los estudios que sobre todo se han centrado en Twitter y establece una comparativa con estudios precedentes. El uso político de Instagram pivota alrededor de la imagen (Quevedo, Portalés-Oliva, Berrocal, 2016) pero un recurso equilibrado a imagen y texto ha sido apuntado como una posible clave de posicionamiento (TiradoGarcía y Doménech-Fabregat, 2021).

En 2019, la situación política en España fue convulsa, y los españoles fueron a las urnas en dos ocasiones en siete meses. La primera el 28 de abril y, debido a la falta de acuerdo por parte de los partidos, se produjo una repetición electoral el 10 de noviembre. Los 350 escaños totales del Congreso se dividieron entre 16 formaciones, creando un escenario multipartidista que apuntó a una situación de inestabilidad para el país.

Este estudio, con un cotejo de resultados de diversas investigaciones, ayudará a los spin doctors y a las fuerzas políticas a ir ajustando cómo debe manejarse, en este caso, Instagram.

\section{Marco teórico}

Las redes sociales se han ligado a la comunicación política en los últimos años, como ágora de comunicación de obligado uso (Perloff, 2014). Estas son una herramienta muy útil para la difusión de este tipo mensajes ya que permiten diversificar y llegar a diferentes tipos de públicos objetivos, y de manera más eficaz. Fue a partir de la campaña de Howard Dean de 2004 (aspirante demócrata estadounidense) cuando se consideró que la web dirigida a los indecisos tuvo un impacto importante, y las presidenciales de 2016 de ese país las catapultaron (Gil de Zúñiga y Chen, 2019). 
80

\subsection{Estrategia política y entretenimiento}

Construir y ejecutar una buena estrategia es clave en política; sin embargo, investigación precedente muestra que ni los partidos políticos ni el gobierno planean suficientemente las medidas desde el punto de vista estratégico (Del Rey, 2019; Alonso, Miquel y Casero, 2016).

En el contexto de una sociedad del entretenimiento (Edelman, 1988), donde diferentes esferas de la vida se impregnan de la necesidad de entretener para difundir contenidos, una de las estrategias más conocidas y usadas en campañas electorales y en la información política es la de la personalización del candidato (López, Marcos y Casero, 2020). Así, el líder debe ser capaz, no solo de ejercer su función política, sino también de entretener, emocionar y sorprender al electorado, muchas veces indeciso (Redondo, Ventura y Berrocal, 2019). Durante la campaña electoral, se suscita interés por los gustos de los candidatos, por su faceta privada: esto deja en segundo plano las propuestas del partido, sus acciones o ideales (Bennet y Segerberg, 2013; Berrocal, Campos y Redondo, 2012).

Con el recurso a la personalización se pretende imprimir en los candidatos la figura del héroe, con procesos de simplificación que atañen tanto a las características de los candidatos, que son difundidos como mensaje mismo, como a una narrativa que entretenga, más que ahonde en idearios y propuestas. Lo que se definió como infoentretenimiento en cuanto a la información (Ferré-Pavia, 2013), en el terreno político ha sido conceptualizado como politainment (Berrocal, 2017).

A menudo, los elementos secundarios de una noticia pasan a ser protagonistas por su tendencia dramática (Rúas y Casero, 2018; Salmon, 2007). Lo mismo ocurre en los mítines, donde lo que destaca es la euforia y la música elegida y no el acto en si o los discursos lanzados (Orejuela, 2009). Otro de los elementos de las campañas dramatizadas es la llamada negative campaing, que consiste en la búsqueda de titulares fáciles, escenificando una lucha constante con las otras formaciones políticas (Haselmayer, 2019). Así detectamos las campañas espectacularizadas: dramatización, personalización, simplificación y negative campaing.

\subsection{El uso político de Instagram}

Instagram fue creada en 2010 por Kevin Sytrom y Mike Krieger. Actualmente, cuenta con más de mil millones de usuarios en el mundo. Si se focaliza en el ámbito español, tenía 16 millones de usuarios en 2019 y había crecido un $6,6 \%$ respecto al año anterior. En 2020, el 76\% de los usuarios de redes en España accede a Instagram (IAB, 2020). Este forma parte, por lo tanto, de la cotidianidad de la población y es un escenario obligado de los mensajes elec- 
torales. Esta red social es de las pocas que evoluciona positivamente, ya que tanto Facebook como Twitter experimentaron una disminución de usuarios entre 2018 y 2019 (The Social Media Family, 2020).

El uso de social media por parte de los partidos políticos, por un lado, automatiza procesos y mejora su eficacia, y por el otro, favorece la participación y crea un vínculo más cercano con la ciudadanía (Suau, 2020; Rúas y Casero, 2018; Marcos, 2018).

La investigación sobre el uso político de Instagram empieza a ser profusa, aun cuando se obtienen resultados contradictorios que demandan un cotejo con más investigaciones. Por ejemplo, los resultados de Pineda, Barragán y Bellido (2020) para las autonómicas andaluzas indican que los partidos tradicionales (PP-PSOE) usaban más esta red, pero en el caso catalán, Puig Piqué (2017) concluye que es más explotada por la nueva política. Nueva y vieja política han sido etiquetas de Ortega y Gasset (conferencia de 1914 en el Teatro de Madrid) recuperadas para la política española y los partidos de nueva formación en el siglo XXI, como Ciudadanos, Podemos y, más recientemente, Vox. La nueva política no siempre se ha identificado con nuevos valores, pues se continúan identificando tintes populistas y patriarcales en su discurso (Caravantes, 2018).

Hay unanimidad académica sobre la explotación de la red por parte de Vox, una estrategia de ataques, personalización populista y emocionalidad que marca un claro uso propagandístico y espectacularizado (López-Rabadán y Doménech-Fabregat, 2021; Carrasco, Sánchez y Trelles, 2020).

Uno de los focos preeminentes ha sido el estudio de los perfiles y usos de los candidatos y cargos públicos, tanto en Europa y EE. UU. como en América Latina (Lozano, 2020; Towner y Lego, 2018). Názaro, Crozzoli y Álvarez (2019), en el análisis de los casos de Macri y Kirchner en Argentina, concluyen que los mensajes visuales simples y desestructurados en Instagram devienen en una ilusión de cercanía, abocada a lo emotivo.

En una red que tiende más a la personalización (Pineda, Barragán y Bellido, 2020), los resultados de estos estudios son coincidentes en cuanto al predominio de la explotación de la imagen personal por parte de los líderes, con un simulacro de espontaneidad y cotidianidad. Si tenemos en cuenta que se considera la personalización una simplificación (Rebolledo, 2017), este proceso de digestión de los mensajes políticos para un público de la era de la desafección política, sobre todo en los jóvenes y hacia los partidos, se refuerza (Cadena Ser, 2021). 
82

\subsection{Política pop y autorreferencia}

La política pop ha sido denominada como un sinónimo de política popular (Mazzoleni y Bracciale, 2018) y como forma moderna de acercamiento a los posibles votantes en una era de predominio de las emociones y la subjetividad. Para Ciaglia y Mazzoni (2014), la política pop se da ante una necesidad de nuevas maneras de comunicar y recrear una intimidad mediatizada, con el objetivo de personificar las acciones políticas.

Para Amado (2016), en lo que esta autora lee como una herencia de la cultura pop, la política toma forma de entretenimiento y espectáculo, con candidatos que se proyectan como superhéroes. También Manfredi, Amado y Waisbord (2021) lo definen como un estilo de comunicación de los entes políticos basado en el espectáculo y el personalismo, fenómenos atribuidos a la tendencia del politainment. Según los autores precedentes, el canal de transvase entre la política pop y los estilemas de la comunicación espectacularizada es claro.

Desde el punto de vista estético, la autorreferencia es «la inclusión del sujeto en la obra» (Álvarez, 2010: 31). Aplicada a los mensajes que se difunden en campaña y a la forma de presentarse de las candidatas y los candidatos, se puede considerar que la autorreferencia se da en tres sentidos impulsados por el politainment. En primer lugar, la citada substitución del mensaje político en sí mismo por las figuras políticas; en segundo, la difuminación del partido en pro de los candidatos celebrities (Quevedo y Portalés-Oliva, 2017), y finalmente, la disminución de los mensajes programáticos y con contenido a favor de escenas de mítines y de actos de campaña. Debemos considerar, además, que, en estos momentos, los actos de campaña suponen altas cotas de ficcionalidad por su detallada preparación.

Estudios precedentes han definido Instagram como una red óptima para la autorrepresentación de los candidatos (Gordillo y Bedillo, 2021). Para estos autores, la imagen de los candidatos actúa en un ámbito de afirmación, pero se aleja de la campaña negativa y de la esfera privada para su caso de elecciones autonómicas 2018.

\section{Diseño metodológico}

El objeto de estudio de este trabajo es la comunicación política de los partidos políticos catalanes y españoles durante la campaña electoral en la red social Instagram. El caso estudiado es el de las elecciones generales 2019.

El objetivo general de la investigación, de corte comparativo, es entender cómo las formaciones seleccionadas han hecho uso de la red social Instagram en sus publicaciones de campaña electoral. El método aplicado es el análisis de contenido tanto interpretativo como cuantitativo. 


\subsection{Objetivos específicos}

Para ahondar en el objetivo general, se plantea analizar qué publicaciones han funcionado mejor en esta red cuantitativamente e interpretar por qué a la luz de su contexto político.

En segundo lugar, comparar el uso de Instagram de cada partido y si en la campaña han volcado más elementos que puedan considerarse espectacularizados, tal como se han definido en el marco teórico.

\subsection{Categorías de análisis}

Como se puede observar en el gráfico 1, las categorías de análisis se dividen en tres apartados.

\section{Gráfico 1. Categorías de análisis}

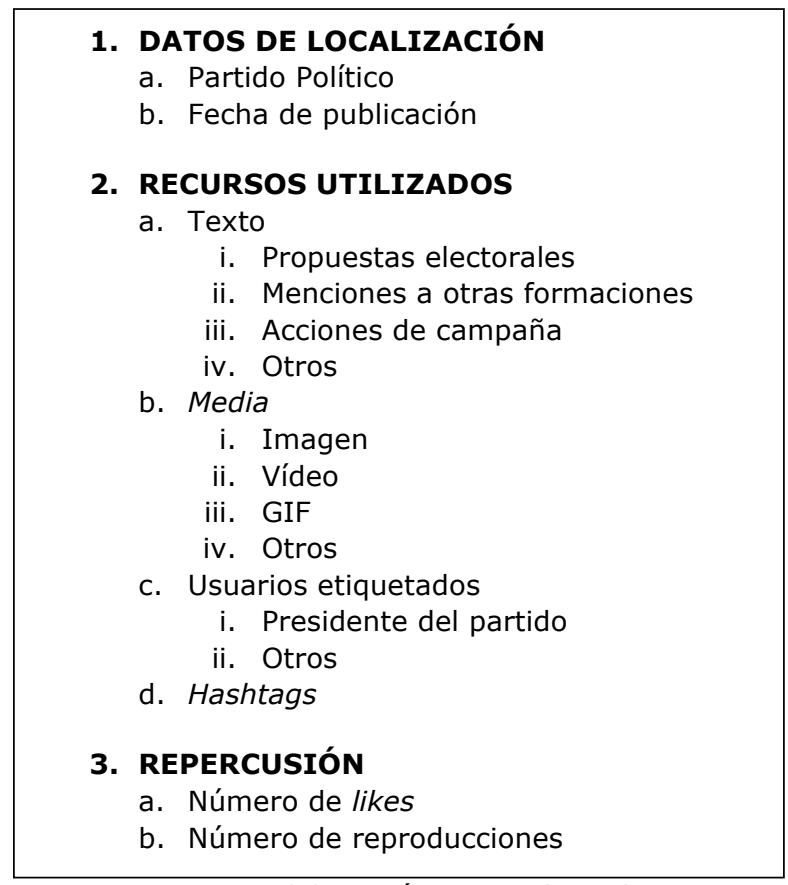

Fuente: elaboración propia (2021).

El primero corresponde a la localización de los elementos (fecha y formación política que publica). El segundo, a los contenidos, y se separan los elementos textuales de los visuales. El análisis de texto anota si se detectan propuestas, menciones a otros partidos o referencias a la campaña, lo que apunta a la simplificación de los mensajes y la negative campaign. En cuanto a los elementos visuales, se anota el recurso a fotografías, animaciones o vídeos, 
que, junto con las etiquetas, permite abordar el recurso a la personalización. El tipo de análisis visual no profundiza en aspectos semióticos.

Completa este apartado la revisión de la personalización a través también del etiquetado. El último apartado anota aspectos cuantitativos del feedback de las publicaciones. En el caso de las imágenes, se contabilizan los likes y en los vídeos, las reproducciones.

\subsection{Selección de la muestra y cronología}

El caso seleccionado ha sido la campaña y poscampaña de las elecciones generales de 2019 en Catalunya, con partidos de ámbito estatal y autonómico: PP, PSOE, Ciudadanos, Vox, Unidas Podemos, Más País, ERC, Junts per Cataluya y CUP. Esta clave general y combinada con partidos también de ámbito catalán permite comparar no solo partidos de la llamada nueva y vieja política, sino con fines y perfiles ideológicos muy distintos.

La cronología de este estudio alcanza del 25 de octubre de 2019 al 7 de enero de 2020, durante y después de las mismas elecciones, hasta la investidura del nuevo presidente del gobierno, Pedro Sánchez. Así, se han localizado un total de 655 publicaciones en Instagram de estos partidos políticos, totales que se expresan por orden de representación parlamentaria en 2019 y según número de seguidores y actividad de publicación.

\section{Resultados}

Como se indicó, se han seleccionado nueve perfiles de Instagram que pertenecen a los nueve partidos estatales y catalanes presentados en las elecciones del 10 de noviembre de 2019. Los resultados se presentan comparando las formaciones en cuatro apartados correspondientes a imágenes; vídeos y personalización; texto y temática de campaña, y etiquetado.

Tabla 1. Muestra de cada partido con número de escaños y seguidores (2019)

\begin{tabular}{|l|c|c|c|c|c|}
\hline \multicolumn{1}{|c|}{ Partido } & Escaños & Seguidores & Posts & Imágenes & Vídeos \\
\hline PSOE & 120 & 96.400 & 108 & 69 & 39 \\
\hline PP & 88 & 100.000 & 97 & 81 & 16 \\
\hline Vox & 52 & 531.000 & 122 & 37 & 85 \\
\hline $\begin{array}{l}\text { Unidas } \\
\text { Podemos }\end{array}$ & 35 & 240.000 & 48 & 24 & 24 \\
\hline ERC & 13 & 77.900 & 53 & 45 & 8 \\
\hline Ciudadanos & 10 & 109.000 & 77 & 53 & 24 \\
\hline Junts per Catalunya & 8 & 40.000 & 62 & 59 & 3 \\
\hline
\end{tabular}




\begin{tabular}{|l|l|l|l|l|l|}
\hline Más País & 3 & 31.700 & 36 & 30 & 6 \\
\hline CUP & 2 & 59.200 & 52 & 25 & 27 \\
\hline
\end{tabular}

Fuente: elaboración propia (2021).

\subsection{Imágenes}

El PSOE publicó 69 imágenes. En el uso de este recurso se observan dos etapas destacables: la primera corresponde al período de elecciones del 10 de noviembre al 28 del mismo mes: un total de 14 publicaciones, donde se sitúa la más popular, con 180.000 likes.

En el caso del Partido Popular, las publicaciones descienden a 97 (81 son imágenes y 16, vídeos). Por lo tanto, se infiere que prefieren el formato fotografía para sus redes sociales, ya que la diferencia entre uno y otro recurso es sustancial. En el caso de las imágenes, se detectaron dos momentos exitosos, que llegan a los 90.000 likes, un patrón que ya se dio en el caso del PSOE: el primero durante los días previos y posteriores a las elecciones y el otro, durante el período de la investidura. La diferencia entre uno y otro partido radica en que el PP es más irregular, ya que hay otros dos picos menos significativos a finales de noviembre y principios de diciembre de ese año. Estos últimos coinciden con unos días en que el PP cargó duramente contra Pedro Sánchez por no comunicarse con ellos como segunda fuerza política estatal.

Vox fue la sorpresa de las elecciones, y parte de su éxito estuvo en el uso minucioso y estudiado de sus redes sociales y, especialmente, de Instagram. Vox es la formación con más publicaciones durante el período analizado: 122 divididas en 37 imágenes y 85 vídeos. Se puede afirmar que las fotografías quedan en segundo plano. En el caso de las imágenes, hay un ascenso en la popularidad desde el primer día que comprende el análisis, que se frena a principios de diciembre y alcanza el pico más alto el 7 de noviembre, con una publicación sobre un discurso de Unidas Podemos y la réplica de Vox, que alcanza 83.000 likes.

Unidas Podemos tiene un total de 48 publicaciones durante el período analizado: 24 imágenes y 24 vídeos que reúnen de media 13.258 «Me gusta». Por primera vez, una formación opta por el equilibrio entre el contenido multimedia y las fotografías. Las imágenes muestran una tendencia baja en el número de «Me gusta», a excepción de 3 que superan los 20.000 likes. La más exitosa es la del 12 de noviembre, dos días después de las elecciones, que remite a un discurso de Pablo Iglesias tras conocer los resultados.

Pasando a los partidos de ámbito catalán, de las 45 menciones de ERC, hay una que destaca por encima de las otras. Es la del día 19 de diciembre, referente a la decisión del Tribunal de Justicia de la Unión Europea dando la 
86

razón al partido sobre la inmunidad de Oriol Junqueras, el expresidente del partido, encarcelado. En total, acumula más de 8.000 «Me gusta».

Ciudadanos ha realizado 77 publicaciones en el período. De estas, 53 son imágenes y 24 vídeos. Hay que aclarar que, dada la dimisión de su exdirigente Albert Rivera, tras los resultados obtenidos el 10 de noviembre, todo lo referente al presidente del partido estará dividido en dos fases: la primera, en que se analiza al barcelonés y una segunda, donde la protagonista es su sucesora entonces, Inés Arrimadas.

Lo que más llama la atención es la publicación del 11 de noviembre que casi triplica los «Me gusta» de la segunda más exitosa. Corresponde a un conjunto de fotografías del adiós de Albert Rivera y acumula más de 26.000 likes.

En las publicaciones de Junts per Catalunya, hay 59 imágenes. El número de «Me gusta» es de más de 4.000 en 2: la del 14 de noviembre y la del 20 de diciembre que hacen referencia a la decisión de la justicia escocesa de dejar a Clara Ponsatí libre sin retirarle el pasaporte y la recogida del acta de parlamentarios europeos de Carles Puigdemont y Antoni Comín. Sin conocer el discurso del partido, no deja de sorprender que los posts más exitosos no hagan referencia a las elecciones o a cuestiones referidas a la formación en España, sino a otros temas internacionales.

Más País es el partido más joven de todos los analizados. La formación creada por Iñigo Errejón nació después de que en Unidas Podemos surgieran opiniones discordantes y se presentó por primera vez el 10 de noviembre. Colgaron 36 publicaciones durante los 75 días analizados: 30 imágenes y 6 vídeos. Como ya se ha dicho, es una de las formaciones con menos actividad en Instagram debido, probablemente, a su reciente constitución. Sin embargo, el número de «Me gusta» que consigue es elevado en comparación con los seguidores que tiene. En promedio consiguen 2.752, pero la publicación más exitosa acumula 8.746 likes y corresponde a la posterior a las elecciones y, por lo tanto, la entrada del partido en la política española.

La CUP es un partido catalán independentista que el 10 de noviembre se presentó a las elecciones después de no hacerlo en abril de ese mismo año. Cabe destacar que es una formación que se considera asamblearia, por lo que no hay un presidente. El análisis referente a este ámbito se ha hecho con Mireia Vehí, portavoz y candidata del partido al Congreso. En cuanto a las publicaciones, hay en total 52, de las cuales 25 son imágenes y 27, vídeos. Las fotografías consiguen de media 3.311 likes, y la más exitosa es la correspondiente al 11 de noviembre, seguida de cerca por la del 5 de enero. Estas aluden al agradecimiento del partido a sus votantes por haber obtenido representación y al primer discurso de Mireia Vehí en el Congreso. 


\subsection{Vídeos y personalización}

Los vídeos del PSOE son 39. Durante la campaña, se puede observar que hay una publicación del 31 de diciembre que alcanza las 13.000 reproducciones, donde se da las gracias a los seguidores. Una de las estrategias más utilizadas en la comunicación política en redes sociales es exaltar al presidente o candidato a través de los posts. Sánchez está en solitario en el 38\% de las publicaciones, sean vídeos o fotografías, y en el 16,7\% acompañado de otros representantes del partido como Adriana Lastra, mientras que en un 45,4\% Sánchez no aparece.

Tres de los vídeos del PP tuvieron un éxito destacable, con alrededor de 60.000 reproducciones De estos, 2 son un ataque al PSOE: uno es una crítica a Pedro Sánchez por el caso ERE y el otro, unas declaraciones antiguas del presidente del Gobierno. Pablo Casado era una de las caras nuevas de la política entonces. Para construir su imagen fueron clave las redes sociales. En ellas, el candidato aparece en los posts casi el mismo número de veces que no lo hace, por lo tanto, su presencia es importante. Hay que destacar que las veces que sí aparece lo hace más en imágenes donde está solo, lo que exalta su imagen. Además, suelen ser fotografías de gran calidad y buscando planos cerrados y ángulos especiales.

Los vídeos de Vox forman el núcleo esencial de su perfil. Hay dos etapas importantes: la primera con una duración de 10 días, del 5 al 14 de noviembre correspondiente a los días previos y posteriores a las elecciones, y la segunda desde finales de diciembre hasta el 7 de enero, cuando Sánchez logra la presidencia. La publicación más exitosa se encuentra en este último período. Corresponde al 4 de enero y es el discurso de Santiago Abascal en el Congreso, de réplica al candidato del PSOE, que acumula más de 400.000 visualizaciones.

Vox ha hecho un gran uso de las redes sociales, pero hay que saber hasta qué punto Abascal ha sido el protagonista. Por primera vez, el número de publicaciones donde no aparece el presidente es superior a las veces que sí lo hace. Esto podría deberse a que no les interese la estrategia de personalización donde todo gira en torno al candidato para crear una imagen reforzada y fuerte. De hecho, la mayoría de las ocasiones donde aparece Santiago Abascal lo hace ante un atril y una gran multitud, y en pocas ocasiones hay una atención minuciosa a las fotografías o los vídeos. En cuanto al perfil de Podemos, se puede afirmar que hay dos picos importantes, con 130.000 reproducciones. El primero en referencia a las elecciones y los días previos y posteriores y el segundo, a principios de enero coincidiendo con la legislatura donde, en este caso, Pablo Iglesias se convierte en vicepresidente. La imagen de Pablo Iglesias ha sido centro de debate en muchas ocasiones: Iglesias no aparece en casi el $70 \%$ de las publicaciones, pero sí lo hace en 3 de cada 10 . No obstante, hay 
88

que incidir en que aparece en más ocasiones en solitario que acompañado por otros representantes del partido. Por primera vez, se observa una gran diferencia entre la aparición del presidente del partido y los posts en que no lo hace. Esto puede suponer que el perfil de Unidas Podemos difunde un contenido menos personalizado.

Sobre el recurso a los vídeos, ERC publica pocos, muestra cierta preferencia por las fotografías. Hay un vídeo más popular que los demás: corresponde al 3 de noviembre y es un fragmento del discurso de Gabriel Rufián en el programa La Sexta Noche, que suma más de 23.000 reproducciones, seguido de cerca por el del 3 de diciembre, con casi 18.500 visualizaciones. En general, los vídeos son fragmentos de entrevistas o discursos en el Congreso, mientras que las imágenes resumen actos del partido y de campaña. Por un lado, Gabriel Rufián no aparece en el $66 \%$ de las publicaciones, mientras que sí lo hace en el $44 \%$ restante. Sin embargo, suele estar acompañado de otros dirigentes y en muchas ocasiones de la secretaria general y portavoz, Marta Vilalta. De hecho, únicamente lo hace solo en una de cada 10 publicaciones. Por otra parte, Oriol Junqueras aparece muy pocas ocasiones, exactamente 4. Dos de ellas en la reproducción de carteles y las otras 2 durante algún proceso judicial estatal o europeo.

En el perfil de Ciudadanos hay 2 publicaciones que sobresalen, con 60.000 reproducciones, correspondientes al día 7 de noviembre y al 4 de diciembre. La primera es un montaje de carácter humorístico de unas declaraciones de Inés Arrimadas a Última Oportunidad de La Sexta, como respuesta al PSOE. La segunda es un nuevo discurso de Arrimadas en el Congreso donde critica las palabras utilizadas por los partidos soberanistas como Bildu o ERC. En cuanto a la aparición del candidato Rivera, está en 6 de cada 10 publicaciones aproximadamente y en más de un $30 \%$ lo hace solo. En cambio, no aparece en el $40 \%$ de los posts. Por otra parte, aunque el anuncio oficial de la presidencia de Arrimadas no fue hasta unos meses después, ya se perfilaba como sucesora. En su caso, no aparece en el $50 \%$ de las publicaciones, mientras que en el resto lo hace acompañada la mayor parte de las veces. De hecho, sólo en una de cada 10 lo hace sola y suelen ser fotografías y vídeos sobre discursos en el Congreso o atendiendo a la prensa.

Sobre los vídeos de Junts per Catalunya, parece que este formato se reserva para ocasiones concretas. Sin embargo, no hay una diferencia significativa entre las reproducciones y los likes de las imágenes, ya que las más exitosas superan los 4.000 «Me gusta» o visualizaciones y el resto acumula cifras inferiores. Esta tendencia es contraria a lo que se había dado hasta ahora, en que las reproducciones solían ser superiores. En cuanto al presidente del par- 
tido, hay que especificar que, al estar Puigdemont fuera del país, será analizado él y también Laura Borràs, cara visible del partido en el Congreso y protagonista de la campaña. Puigdemont sólo aparece en el 20\% de las publicaciones y lo hace principalmente acompañado, normalmente de Antoni Comín o de algún representante del partido desplazado a Bélgica. En cambio, la presencia de Laura Borràs es muy diferente: ella aparece en el $50 \%$ de los posts, aunque un $30 \%$ de las veces lo hace acompañada.

En lo que respecta a los vídeos del perfil de Más País, hay uno que destaca por encima del resto: el spot oficial del partido en las elecciones. Los otros 5 acumulan menos reproducciones, pero aun así son exitosos, ya que en promedio alcanzan más de 7.000 visualizaciones. Las temáticas que difunden en este formato son vídeos publicitarios, discursos, actos solidarios en los que participa el partido y del cierre de campaña.

Atendiendo a la aparición de Errejón, no aparece en el 44\% de las publicaciones y sí lo hace en el 66\%. Sin embargo, la mayoría de las veces lo hace acompañado, ya que sólo en un $16 \%$ de las ocasiones lo hace solo y suelen ser discursos en el Congreso o fragmentos de entrevistas. Cuando está acompañado, lo hace normalmente de la exalcaldesa de Madrid, Manuela Carmena, que era otra cara visible de la formación.

El caso de los vídeos de la CUP, sin embargo, es diferente. Aunque hay un gran equilibrio entre los formatos utilizados, mantienen una regularidad más estricta en el número de visualizaciones. Esto no descarta que algunos hayan gustado más, como es el caso del del 5 de enero con más de 27.000 reproducciones y que corresponde al primer discurso entero de Mireia Vehí. También fue exitoso el del 5 de noviembre sobre una respuesta de Vehí durante el debate en TV3 o el del 6 de noviembre con el discurso minuto de oro de Vehí del debate. Destaca que en el 63\% de las publicaciones, Mireia Vehí no aparece, mientras que en el $37 \%$ restante, sí. Sin embargo, lo hace sola y normalmente corresponden a publicaciones sobre debates electorales o discursos en el Congreso. También se localizan infografías con mensajes claros referentes a manifestaciones, clamores de libertad o convocatorias de actos del partido.

\subsection{Texto y temática de campaña}

En cuanto al texto de los posts del PSOE, los mensajes que más destacan son las acciones de campaña que incluyen debates y mítines; después, las propuestas electorales, que son expuestas de manera clara en 18 posts $\mathrm{y}$, por último, las menciones a otras formaciones, que en este caso son el Partido Popular y ERC. 
Del texto que acompaña a las publicaciones del PP, hay que resaltar que, en 45 de 97 mensajes, el partido alude a otra formación, en especial a su rival más directo, el PSOE.

En el caso de Vox, sólo en 8 de las 22 dejan constancia de alguna de sus medidas programáticas, mientras que en 31 publicaciones se localizan actos de campaña como mítines o fragmentos y minutos de oro de los debates electorales. En cuanto a las menciones de otras formaciones, de las 22 que hay, en 16 ocasiones el PSOE es el protagonista.

La gran mayoría de las publicaciones de Podemos se refieren a denuncias y problemas sociales. Sin embargo, hay un número alto que se centra en acciones de campaña, recoge discursos, entrevistas y mítines. Las propuestas electorales caen, siendo detectadas solo en 6 de las 48 publicaciones, por tanto, quedan en un segundo plano respecto a las otras categorías. Aludiendo al texto de las publicaciones de ERC, destaca la ausencia de propuestas electorales. Las referencias a otros partidos son 3 y todas de carácter crítico hacia el PSOE. En este caso, sí que dan mucha importancia a las acciones de campaña.

En el caso de Ciudadanos, las menciones a otros partidos, en este caso, son numerosas. De las 15 veces que lo hacen, 14 son referidas al PSOE y 1 al PP. Sin embargo, en varias ocasiones, el partido de Sánchez es mencionado con otros como Junts per Catalunya, Unidas Podemos o con el PNV. Las propuestas electorales son, de nuevo, la categoría menos utilizada.

En lo que respecta al texto en Junts, hay una destacable ausencia de propuestas electorales, ya que no hay ninguna en las 62 publicaciones. Cuando se menciona a otros partidos, en 6 de 7 ocasiones aluden al PSOE y una a ERC y la CUP, conjuntamente. También se menciona a Unidas Podemos, pero siempre junto al partido de Sánchez. En cuanto a las acciones de campaña, el 29\% de los posts las representan. Suelen ser mítines y desplazamientos del partido.

En el perfil de Más País, se localiza la primera vez que un partido hace más referencia a sus propuestas electorales que a cualquier otra categoría. Esto indica una voluntad de que los seguidores o los posibles votantes tengan una idea de lo que defienden, ya bien porque se trata de una nueva formación o por una voluntad de gestionar la narrativa de campaña de manera distinta.

En los textos de la CUP destacan las acciones de campaña, ya que es un partido que las documenta de manera extensa, con más de una publicación para cada mitin o encuentro. También se hallan muchos posts referentes a manifestaciones, reuniones o declaraciones de unidad independentista.

\subsection{Etiquetado}

En lo que respecta al etiquetado, durante el período analizado, el PSOE ha utilizado 110 etiquetas. Las más utilizadas son \#psoe, seguida de \#ahorasi, 
lema del partido para estas elecciones. Otras como \#votapsoe o \#10-N también son repetidas, pero las 106 restantes aparecen menos de 10 veces en el recuento total.

En el caso del PP, son 124 repetidas a lo largo de 97 publicaciones, y 5 se acercan a las 80 apariciones. Esto supone estar en el $82 \%$ de los posts, lo que da por supuesto que hay etiquetas comodín que se utilizan sea cual sea el tema de la imagen o del vídeo. Estas, además, son conceptos fáciles de recordar y buscar como «política» 0 «España».

Vox utiliza etiquetas en cada post y 3 destacan por encima de las otras: \# españaviva, \#españasiempre y \#Vox, que aparece en la mitad de los vídeos e imágenes del perfil. En total hay 178, la mayoría de las cuales no superan las 2-3 apariciones.

Durante el período analizado del perfil de Unidas Podemos, hay 99 etiquetas, pero sólo 16 superan más de 2 menciones. De hecho, hay 7 que aparecen 3 veces, mientras que el resto se mueven entre las 5 y las 26 ocasiones. La que más destaca es \#podemos, seguida de \#sisepuede, que coincide con el eslogan del mismo partido. Un dato curioso es que, aunque el presidente es Pablo Iglesias, su etiqueta aparece sólo 2 veces mientras que \#IreneMontero lo hace en 5 ocasiones.

Respecto a las etiquetas utilizadas por ERC, hay un total de 44 a lo largo de las 53 publicaciones analizadas. De estas, destacan 13 que son las que aparecen más de 5 veces, ya que las otras lo hacen entre una y dos ocasiones. De entre todas, las 3 más populares lo son con 45 apariciones cada una: \#llibertatpresospolitics, \#llibertatpresespolitiques y \#independencia. Son 3 etiquetas que definen la ideología del partido. También hay algunas como \#llibertat o \#republicacatalana que tienen menos incidencia, pero no dejan de ser importantes. Además, hay una en referencia a Oriol Junqueras o el mismo eslogan de campaña «Tornem-hi».

En el caso de las etiquetas, Ciudadanos ha usado 76, aunque sólo 4 superan las 5 apariciones. Entre las más recurrentes está \# españaenmarcha, eslogan del partido para las elecciones, el nombre de la misma formación \#ciudadanosCs y la fecha del 10 de noviembre.

Sobre las etiquetas utilizadas por Junts per Catalunya, se trata del partido que menos recurre a ellas. En total, 21, de las cuales sólo 9 aparecen más de una vez. Se trata del nombre del partido, el lema para el 10-N Ni un voto atrás o, referente a los presos y exiliados, \#freetothom (libre todo el mundo). La más utilizada es la de su nombre y acumula 33 apariciones, en el 53\% de las publicaciones. 
En la revisión de las etiquetas de Más País, se localizaron 52, pero sólo 8 aparecen más de una vez. De entre estas, destaca el nombre del mismo partido y 2 referidas al voto: \#votamaspais y \#votadistinto.

En el caso de la CUP, utilizan pocas etiquetas, de las que destacan 2: \#10-N y \#larojaingovernable, lema del partido en las elecciones. Otras 41 aparecen entre una y 3 veces y se adaptan a cada publicación, según los temas que tratan.

\section{Conclusiones y discusión}

El objetivo principal de este trabajo era analizar los perfiles de Instagram de los partidos políticos estatales y autonómicos catalanes para establecer comparativamente las diferencias de la gestión que hacen de la red. Tras estudiar 655 publicaciones, se puede afirmar que se localizan diferencias entre ellos y publican con objetivos diversos, según los intereses de cada formación. En primer lugar, cabe destacar que hay disparidad en el uso que hacen de las redes en cuanto a objetivos comunicacionales, y concretamente Instagram, los partidos de la «vieja política» (PSOE y PP) y los de la (entonces) «nueva política» (Vox, Unidas Podemos, Ciudadanos y Más País). Los primeros lo utilizan como una herramienta más, aunque el partido de Casado en la última etapa se modernizó. En cambio, el segundo grupo lo utiliza como una vía de reivindicación de sus ideas sin abandonar la publicación de notas divulgativas, sobre todo durante el periodo electoral. Los partidos autonómicos analizados adoptan este aire reivindicativo centrado en la independencia y en la libertad de los presos, incluso más que en el propio partido.

Autores como Bennet (2013), Edelman (1988), Maarek (2014) o Newman (1994) destacan desde hace décadas la personalización como una herramienta política efectiva, pero no siempre lo afirmaron en un momento en que las redes multiplicaron exponencialmente ese efecto. La población tiene más interés por la vida privada del político que por la profesional (Alonso y Casero, 2018). En el caso que nos ocupa, se ha podido observar que en partidos como Ciudadanos hay una intención de recurrir a esta estrategia. Otros, como Más País y el PSOE, se encuentran en situaciones similares, mientras que todo lo contrario ocurre con la CUP o ERC, lo que confirma a nivel internacional una diferencia en el uso de redes dependiendo de las tendencias políticas (Rivas y García, 2020; Cartes, 2018).

Además de la personalización, se vio como el PP ha destacado en la aplicación de la campaña negativa, de ataque al oponente, más que de propuestas propias.

En cuanto a los contenidos vehiculados, en ningún caso, excepto el de Más País, se localizan propuestas programáticas, sino que los mítines y actos 
de campaña cobran protagonismo. Se trata de una narrativa en que el espectáculo de la campaña se sobrepone a lo que representa ideológicamente el partido. Si el candidato desdibuja al partido y la narrativa de campaña a los contenidos programáticos, nos situamos ante lo que definimos como escenificación autorreferencial. Desde este punto de vista, se coincide en parte con Selva y Caro (2017) en lo que ellos llaman predominio de los «usos de escenario» o con el planteamiento de Gordillo y Bellido (2021) sobre selfrepresentation.

Este trabajo ha interpretado en qué ocasiones se utiliza el vídeo y en qué la imagen y por qué. La mayoría de los partidos optan por la imagen como formato más recurrente mientras que otros como Vox se centran en el vídeo, generando un rasgo distintivo de su perfil, hecho que han confirmado otras investigaciones (López Rabadán y Doménech, 2021; Belim, 2020). Unidas Podemos y la CUP son los partidos que los difunden más equilibradamente. Sea voluntario o no, consiguen una equiparación casi perfecta entre vídeo e imagen, lo que aporta variedad a la cuenta. En las otras formaciones, se concluye un uso diferenciado entre formatos: los vídeos se reservan para ocasiones especiales, resúmenes de mítines o para buscar la emoción del espectador, mientras que la imagen aparece como más espontánea, sea escenificada o no.

En cuanto a las limitaciones de la investigación, este estudio se enmarca en un contexto autonómico, como los citados de Pineda, Barragán y Bellido (2020) y Carrasco, Sánchez y Trelles (2020). La muestra de posts, limitada, corresponde con los totales del período y es asimilable a la usada por los primeros autores de este párrafo. Las situaciones contextuales, tanto sociales como internas de los partidos, pueden originar resultados dispares entre diferentes estudios.

Esta investigación se suma a lo que se ha profundizado hasta la fecha sobre todo en el uso político de Instagram (Kwon, 2020; Vossen, 2019) y de Twitter (Percastre, 2018; Alonso, Marcos y Casero, 2017) y contribuye a generar un marco adecuado a los estudios transmediáticos (Moya, 2020; Ohme, 2019a), ya que los contenidos políticos, y hasta los mismos contenidos ciudadanos se mueven de unas redes a otras, con o sin cambios de forma.

Desde el punto de vista de la política, nunca en la historia ésta había sido tan sinónimo de comunicación, con líderes ficcionalizados y ciudadanos constructores de sentidos (Oser y Boulianne, 2020).

\section{Referencias bibliográficas}

ALONSO-MuÑOZ, L. y CASERO-RIPOLLÉS, A. (2018). Political agenda on Twitter during the 2016 Spanish elections: issues, strategies, and users' responses. Communication \& Society, 31(3), 7-25. 
Alonso-Muñoz, L., MARCos-GarcíA, S. y CASERo-RipollÉS, A. (2017). Political leaders in (inter)action. Twitter as a strategic communication tool in electoral campaigns. Trípodos, 39, 71-90. https: //tinyurl.com/3hbab6tz

Alonso-MuÑOZ, L., MiQuEl-SEGARRA, S. y CASERO-RIPOLlÉS, A. (2016). Un potencial comunicativo desaprovechado. Twitter como mecanismo generador de diálogo en campaña electoral. Obra digital: revista de comunicación, 11. doi.org/10.25029/od.2016.100.11

ÁlVAREZ FALCóN, L. (2010). La autoreferencialidad de la experiencia estética. Fedro, revista de estética y teoría de las artes, 9, 30-42.

https: / / tinyurl.com/4xmexszp

Amado, A. (2016). Política pop. De líderes populistas a telepresidentes. Ariel.

BELIM, C. (2020). «In the Land of Elections, the Populist Man Is King»: The Online Communication of Basta and Vox in the 2019 European Elections. Trípodos, 49, 109-128. doi.org/10.51698/tripodos.2020.49p109-128

BENNETT, L.W. y SEGERBERG, A. (2013). The Logic of connective action: digital media and the personalization of contentious politics. Cambridge University Press.

Berrocal, S. (2017) (Ed.). Politainment. La política espectáculo en los medios de comunicación. Tirant Humanidades.

CADENA SER (22 de julio de 2021). Un macrosondeo refleja que el 92\% de los jóvenes no se siente escuchado por los partidos políticos. https: //tinyurl.com/ymjtje8c

CARAVAnTES. S. (2018). New versus Old Politics in Podemos: Feminization andMasculinized Party Discourse. Men and Masculinities, 22(3), 465-490. doi.org/10.1177/1097184X18769350

Berrocal, S., CAmpos Domínguez, E. y REdondo García, M. (2012). El infoentretenimiento político en Internet: la presencia de cinco líderes europeos en Youtube. RIPS, 11(4), 107-131.

https: / / tinyurl.com/4jznk2d5

CARrASCO, R., SÁNCHEZ DE LA NIETA, M.A. y TRELlES, A. (2020). Las elecciones al parlamento andaluz de 2018 en Instagram: partidos políticos, periodismo profesional y memes. Revista Mediterránea de Comunicación, 11(1), 75-85, doi.org/10.14198/MEDCOM2020.11.1.19

CARTES BARRoso, M.J. (2018). The use of Instagram by Catalan political parties during the referendum of 1 October. Revista de Comunicación de la SEECI, 47, 17-36. doi.org/10.15198/seeci.2018.0.17-36

Ciaglia, A. y Mazzoni, M. (2014). Pop-politics in times of crises: The Italian tabloid press during Mario Montis's government. European Journal of Communication, 29(4), 449-464.

doi.org/10.1177\%2F0267323114529535 
CostA-SÁNCHEZ, C., RodRÍGUEZ-VÁZQUEZ, A.I. y LóPEZ-GARCÍA, X. (2020). Transmedia or repurposing journalism? News brands in the era of convergence. Compared study of Greek elections coverage by El País (ES), The Guardian (UK), La Repubblica (IT), and Público (PT).Journalism, 21(9), 1300-1319. doi.org/10.1177/1464884917734053

EDELMAN, M. (1988). Constructing the political spectacle. University of Chicago Press.

FERRÉ-PAVIA, C. (2013) (Ed.). Infoentretenimiento. El formato imparable de la era del espectáculo. Editorial UOC.

GIL DE ZÚÑIGA, H. y CHEN, H.T. (2019). Digital Media and Politics: Effects of the Great Information and Communication Divides. Journal of Broadcasting and Electronic Media, 63(3), 365-373.

doi.org/10.1080/08838151.2019.1662019

Gordillo, M.T. y BELLIDO, E. (2021). Politicians self-representation in Instagram: the professional and humanized candidate during 2019 Spanish elections. OBS Observatorio Journal, 15(1), 109-126.

HASELMAYER, M. (2019). Negative campaigning and its consequences: a review and a look ahead. French Politics, 17, 355-372.

doi.org/10.1057/s41253-019-00084-8

IAB SPAIN (2020). Estudio Anual de Redes Sociales 2020. IAB.

KWON, H. (2020). Political Use of Instagram: The Relationships Between Motivations, Frequent Use, Incidental News Exposure and Online Political Participation. Universidad de Nuevo México, Albuquerque, EEUU.

LÓPEZ-MERI, A., MARCOS-GARCÍA, S. y CASERO-RIPOLLÉS, A. (2020). Estrategias comunicativas en Facebook: personalización y construcción de comunidad en las elecciones de 2016 en España. Doxa Comunicación, 30, 229-248. doi.org/10.31921/doxacom.n30a12

LÓPEZ RABADÁN, P. y DOMÉNECH FABREGAT, H. (2021). Nuevas funciones de Instagram en el avance de la «política espectáculo». Claves profesionales y estrategia visual de Vox en su despegue electoral. Profesional de la información, 30(2), e300220. doi.org/10.3145/epi.2021.mar.20

LOZANO, C. (2020) Comunicación política en Instagram durante la emergencia sanitaria por Covid 19. El caso de Otto Sonnenholzner en Ecuador. Revista ComHumanitas, 11(3), 75-95. doi.org/10.31207/rch.v11i3.259

MAAREK, P. (2014). Politics 2.0: New Forms of Digital Political Marketing and Political Communication. Trípodos, 34, 13-22. https: / /tinyurl.com/mn93wjdz

MANFREDI, J.L., AMAdo-SuÁREZ, A. y WASBORD, S. (2021). Presidential Twitter in the face of Covid-19: between populism and pop politics. Comunicar, 66, 79-90. doi.org/10.3916/C66-2021-07 
MARCOS GARCÍA, S. (2018). Las redes sociales como herramienta de la comunicación política. Usos políticos y ciudadanos de Twitter e Instagram. Universitat Jaume I.

MAZZOLENI, G. y BRACCIALE, R. (2018). Socially mediated populism: the communicative strategies of political leaders in Facebook. Palgrave Communication 4, 50. doi.org/10.1057/s41599-018-0104-x

MEILÁN, X. (2018). Del SMS a la observación colectiva: Nuevas tecnologías de la información y observación electoral en América Latina. Latin American Research Review, 53(2), 273-286. doi.org/10.25222/larr.353

MoyA, E. (2020). Transmedia and New Politics. Isegoría, 0, 62, 55-74. doi.org/10.3989/isegoria.2020.062.03

NEWMAN, B. (1994). The marketing of the president. Sage.

NÁZARO, A., Crozzoli, F. y Álvarez-NoBEll, A. (2019). Comunicación política digital en Instagram. Los casos de Cristina Fernández de Kirchner y Mauricio Macri en Argentina. Revista Internacional de Relaciones Públicas, 18(9), 5-28. https: / / tinyurl.com/mr2epbpy

OHME, J. (2019a). Updating citizenship? The effects of digital media use on citizenship understanding and political participation. Information, Communication \& Society, 22(13), 1903-1928. doi.org/10.1080/1369118X.2018.1469657

OHME, J. (2019b). When digital natives enter the electorate: Political social media use among first-time voters and its effects on campaign participation. Journal of Information Technology \& Politics, 16(2), 119-136. doi.org/10.1080/19331681.2019.1613279

OREJUELA, S. (2009). Personalización política: la imagen del político como estrategia electoral. Revista de Comunicación, 8, 60-83.

OSER, J. y BoUliannE, S. (2020). Reinforcement Effects between Digital Media Use and Political Participation: A Meta-Analysis of Repeated-Wave Panel Data. Public Opinion Quarterly, 84, 355-365. dx.doi.org/10.1093/poq/nfaa017

PERCASTRE MENDIZABAL, S.J. (2018). Comunicación política electoral digital. Twitter y redes sociales digitales en campaña: el caso de las elecciones intermedias en México en el año 2015. Universitat Pompeu Fabra.

PERLOFF, R.M. (2014). The Dynamics of political communication media and politics in a digital age. Routledge.

PinedA, A., BARRAGÁN, A. y BELlido, E. (2020). Representación de los principales líderes políticos y uso propagandístico de Instagram en España. Cuadernos.info, 47, 80-110, doi.org/10.7764/cdi.47.1744

PUIG PIQUÉ, C. (2017) Anàlisi de la comunicació política a Instagram durant la campanya electoral de les eleccions del 21D per part dels líders candidats a 
governar amb major representació al Parlament de Catalunya. Universitat Autònoma de Barcelona.

QUEVEDO, R. y PORTALÉS-OLIVA, M. (2017). Imagen y comunicación política en Instagram. Celebrificación de los candidatos a la presidencia del Gobierno. El profesional de la información, 26(5), 916-927.

doi.org/10.3145/epi.2017.sep.13

QueVEDO, R., PORTALÉS-OLIVA, M. y BERROCAL, S. (2016). El uso de la imagen en Twitter durante la campaña electoral municipal de 2015 en España. Revista Latina de Comunicación Social, 71, 81-107.

dx.doi.org/10.4185/RLCS-2016-1085

REBOLLEDO, M. (2017). La personalización de la política: una propuesta de definición para su estudio sistemático. Revista de Comunicación, 16(2), 147-176.

REDONDO, M., VENTURA, M. y BERROCAL, S. (2020). Nuevos roles del líder político en los programas televisivos de infoentretenimiento. Doxa Comunicación, 30, 37-57. doi.org/10.31921/doxacom.n30a2

REY MORATÓ, J. (2019). Comunicación política, internet y campañas electorales: de la teledemocracia a la ciberdemocracia. Tecnos.

RIVAS DE RoCA, R. y García GoRdiLlo, M. (2020). Thematic Agenda on Twitter in the 2019 European Parliament Elections: A Comparative Study Between «Spitzenkandidaten» and National Candidates. Trípodos, 49, 29-49. doi.org/10.51698/tripodos.2020.49p29-49

RÚAS ARAÚJO, X. y CASERO-RIPOLLÉS, A. (2018). Comunicación política en la época de las redes sociales: lo viejo y lo nuevo, y más allá. AdComunica, 16, 21-24. doi.org/10.6035/2174-0992.2018.16.2

SALMON, C. (2007). Storytelling: la máquina de fabricar historias y formatear las mentes. Editorial Península.

SELVA RuIZ, D. y CARO, L. (2017) Uso de Instagram como medio de comunicación por parte de los diputados españoles: la estrategia de humanización en la «vieja» y la «nueva» política. Profesional de la información, 26(5), 903-915. doi.org/10.3145/epi.2017.sep.12

Social Media FAmily, The (2020). IV Estudio sobre los usuarios de Facebook, Twitter e Instagram en España. https: / / tinyurl.com/2s37bt2x

SuAu GoMILA, G. (2020). Microblogging electoral: usos y funciones en Twitter de la política emergente española en las campañas electorales del 20 de diciembre de 2015 y del 26 de junio de 2016. Universitat Pompeu Fabra.

TIRADO-GARCÍA, A. y DOMÉNECH-FABREGAT, D. (2021). Interacción imagen fotográfica-texto como estrategia de comunicación política en Instagram durante la campaña del 28A de 2019 en España. Profesional de la información, 30(2). doi.org/10.3145/epi.2021.mar.23 
TOWNER, T.L. Y LEGO, C. (2018) Picture perfect? The role of Instagram in issue agenda-setting during the 2016 presidential primary campaign. Social Science Computer Review, 36(4), 484-499. doi.org/10.1177/0894439317728222

VosSEN, K.C. (2019). Political Framing and the Ethos of Justin Trudeau on Instagram: An Heroic Storytelling Between Emotion and Celebrity Politics. Communiquer, 26, 1-22. doi.org/10.4000/communiquer.4309 